\title{
Jaccoud's Arthropathy
}

\author{
Jessica Cruz Whitley, MD and Paul Aronowitz, MD
}

Department of Internal Medicine, University of California, Davis, Sacramento, CA, USA.

KEY WORDS: Jaccoud's arthropathy; Systemic lupus erythematous; Deforming arthropathy.

J Gen Intern Med 33(9):1583

DOI: $10.1007 / \mathrm{s} 11606-018-4559-7$

(c) Society of General Internal Medicine 2018

23-year-old woman with a 7-year history of systemic A lupus erythematosus (SLE) complicated by lupus nephritis presented with abdominal distension. She was found

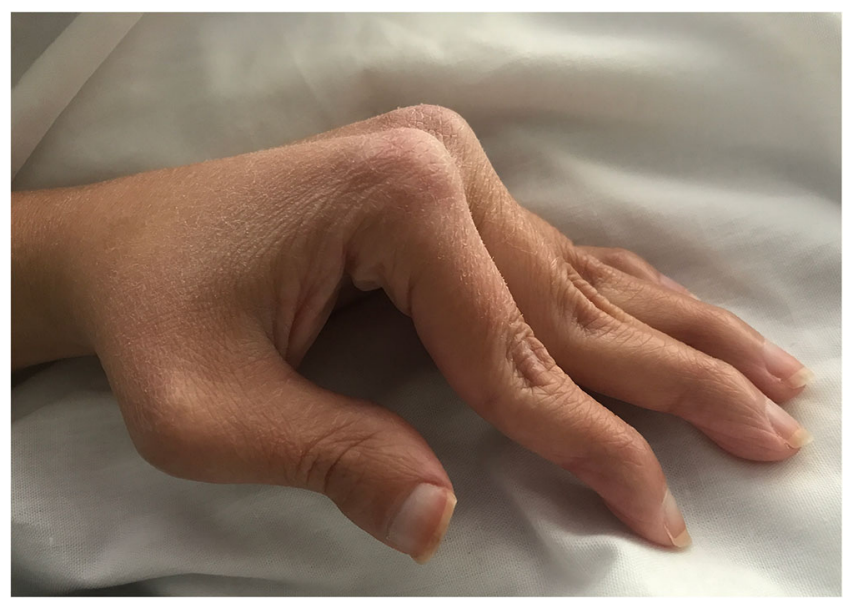

Fig. 1 Left hand with Jaccoud's arthropathy

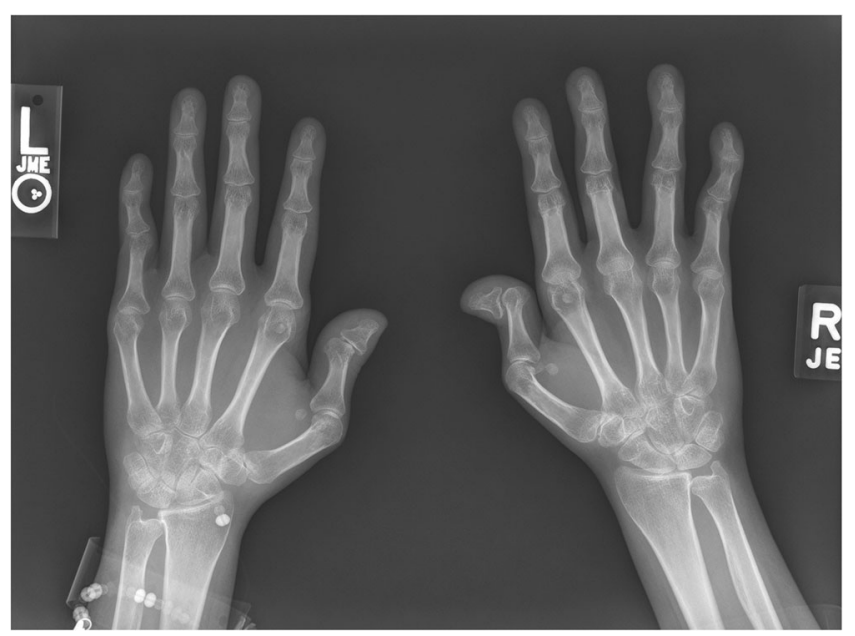

Fig. 2 Radiographic film of both right and left hands with subluxation of the interphalangeal joint of the first finger of the right greater than left hand; no focal bone erosions

Published online July 9, 2018 to have worsening renal function with nephritic range proteinuria and ascites. Musculoskeletal examination revealed Zshaped thumbs, swan neck deformities of the distal interphalangeal joints, and reduced flexion at the metacarpophalangeal (MCP) joints, suggestive of Jaccoud's arthropathy (JA) (Fig. 1). Radiographic films of bilateral hands confirmed non-erosive disease (Fig. 2).

SLE is a chronic inflammatory disease, which can affect the skin, kidneys, nervous system, serous membranes, and other organs. Arthropathy is the most common and earliest manifestation in SLE, affecting $90 \%$ of patients with variable degree of articular involvement. ${ }^{1} \mathrm{JA}$ is a deforming, non-erosive arthritis, occurring in 10-35\% of SLE patients. While JA can involve all joints, it most commonly manifests as severe deformations of the hands, including ulnar deviation, swan neck and boutonniere deformities, and Zdeformity of the thumb, with multiple non-erosive subluxations. Ulnar drift with subluxation of the MCP joint is often the first sign, whereas swan neck, boutonniere, and Z-deformities may occur at later stages. ${ }^{1}{ }^{2}$

Corresponding Author: Jessica Cruz Whitley, MD; Department of Internal Medicine University of California, Davis, Sacramento, CA, USA (e-mail: jcruzwhitley@ucdavis.edu).

\section{Compliance with Ethical Standards:}

Conflict of Interest: The authors declare that they do not have any conflicts of interest.

\section{REFERENCES}

1. Pipili C, Sfritzeri A, Cholongitas E. Deforming arthropathy in systemic lupus erythematosus. Eur J Intern Med, 2008. 19(7): p. 482-7.

2. van Vugt RM, et al., Deforming arthropathy or lupus and rhupus hands in systemic lupus erythematosus. Ann Rheum Dis, 1998. 57(9): p. 540-4. 